\title{
DINAMIKA PELEPASAN NITROGEN EMPAT JENIS PUPUK UREA PADA KONDISI TANAH TERGENANG
}

\section{Dynamics of Nitrogen Release by Four Types of Urea in Flooded Condition}

\author{
Arief Hartono1)*, Budi Nugroho'), Desi Nadalia1) dan Afifah Ramadhani2) \\ 1) Departemen Ilmu Tanah dan Sumberdaya Lahan, Fakultas Pertanian, IPB University, Jl. Meranti Kampus IPB \\ Darmaga Bogor 16680 \\ 2) Program Studi Manajemen Sumberdaya Lahan, Departemen Ilmu Tanah dan Sumberdaya Lahan, Fakultas \\ Pertanian, IPB University, Jl. Meranti Kampus IPB Darmaga Bogor 16680
}

\begin{abstract}
Urea fertilizer is the most widely used source of nitrogen $(N)$ in Indonesia, including in paddy fields. Urea is a watersoluble $N$ fertilizer, so the use of urea in paddy fields needs to be studied in relation to the release of fertilizer. In this study, urea with different formulations was used those were urea Kujang and Pusri as conventional urea, while urea prill and granule as modified urea containing 0.10 and $0.50 \%$ formaldehyde, respectively. The method in this study was the incubation and washing method. Incubation was carried out for 7, 14, 28, 45, 60, and 90 days and washing was conducted at the end of each incubation period. The results of washing were determined for the content of ammonium and nitrate. The results showed that the release of $N$ in the form of ammonium and nitrate among urea fertilizer types were not significantly different. The results of total leached $N$ showed that the highest value was obtained by granule urea at $78.0 \mathrm{mg} \mathrm{tube}^{-1}$, then followed by prill urea at $75.2 \mathrm{mg}$ tube ${ }^{-1}$, Kujang urea at $71.5 \mathrm{mg}$ tube ${ }^{-1}$, and Pusri urea at $68.4 \mathrm{mg}$ tube $e^{-1}$. Based on the results of the first-order kinetic equation, The maximum release and constant rate were revealed. The highest value of maximum release was obtained by granule urea at 94.6

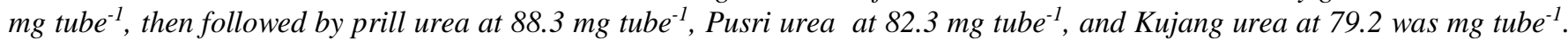
As for the rate constant the highest value of rate constant was obtained by urea Kujang at 0.0349 day $^{-1}$, followed by prill urea and Pusri urea at 0.0256 day $^{-1}$, and granule urea at 0.0253 day $^{-1}$. The result suggested that urea treated with formaldehyde especially in the form of granule tended to slow down the release of $N$ indicated by the lowest value of the rate constant of $N$ released.
\end{abstract}

Keywords: Anerobic, conventional, granul, Latosol

\section{ABSTRAK}

Pupuk urea merupakan sumber hara nitrogen $(\mathrm{N})$ yang paling banyak digunakan di Indonesia, termasuk pada lahan sawah. Urea merupakan pupuk $\mathrm{N}$ yang larut air sehingga penggunaan urea di sawah perlu dikaji dalam hubungannya dengan pelepasan pupuk. Di dalam penelitian ini digunakan urea dengan formulasi berbeda yaitu pupuk urea Kujang dan Pupuk Sriwijaya (Pusri) yang merupakan urea konvensional dan urea prill dan granul yang merupakan urea modifikasi yang mengandung formaldehida masing-masing 0.10 dan $0.50 \%$. Tujuan penelitian ini adalah untuk mengevaluasi pelepasan $\mathrm{N}$ dari tipe urea konvensional dan urea yang diberi formaldehida pada kondisi tanah tergenang. Metode penelitian yang digunakan adalah inkubasi dan pencucian. Inkubasi dilakukan selama 7, 14, 28, 45, 60, dan 90 hari serta dilakukan pencucian pada setiap akhir masa inkubasi. Hasil pencucian ditetapkan kandungan amonium dan nitrat. Hasil penelitian menunjukkan bahwa pelepasan $\mathrm{N}$ dalam bentuk amonium dan nitrat antar perlakuan pupuk urea tidak berbeda nyata. Hasil total $\mathrm{N}$ tercuci menunjukkan nilai paling tinggi diperoleh oleh urea granul sebesar $78.0 \mathrm{mg}$ tabung $^{-1}$, kemudian disusul oleh urea prill 75.2 mg tabung $^{-1}$, urea kujang sebesar $71.5 \mathrm{mg}$ tabung $^{-1}$, dan urea pusri sebesar $68.4 \mathrm{mg}$ tabung$^{-1}$. Berdasarkan hasil persamaan first order kinetic, diperoleh nilai pelepasan maksimum dan konstanta kecepatan. Nilai pelepasan maksimum tertinggi dimiliki oleh urea granul sebesar 94.6 mg tabung ${ }^{-1}$, kemudian urea prill sebesar 88.3 mg tabung $^{-1}$, urea Pusri sebesar 82.3 mg tabung ${ }^{-1}$, dan urea Kujang sebesar 79.2 mg tabung $^{-1}$. Sementara untuk nilai konstanta kecepatan, konstanta kecepatan tertinggi diperoleh pada urea kujang sebesar 0.0349 hari $^{-1}$, kemudian dilanjutkan oleh urea prill dan pusri sebesar 0.0256 hari $^{-1}$, dan urea granul sebesar 0.0253 hari ${ }^{-1}$. Hasil penelitian menunjukkan bahwa urea yang diperlakukan dengan formaldehida terutama dalam bentuk granul cenderung memiliki kemampuan untuk memperlambat proses pelepasan $\mathrm{N}$ yang ditunjukkan dengan nilai konstanta kecepatan pelepasan $\mathrm{N}$ yang paling rendah.

Kata kunci: Anerobik, granul, konvensional, Latosol

\section{PENDAHULUAN}

Nitrogen (N) merupakan salah satu unsur hara penting bagi tanaman. Tanaman menyerap $\mathrm{N}$ dalam bentuk amonium $\left(\mathrm{NH}_{4}{ }^{+}\right)$dan nitrat $\left(\mathrm{NO}_{3}{ }^{-}\right)$. Secara alami, sumber $\mathrm{N}$ di dalam tanah berasal dari bahan organik sisa-sisa dekomposisi dari makhluk hidup, air hujan, dan hasil fiksasi
N-simbiotik/non simbiotik. Di dalam tanah, unsur $\mathrm{N}$ bersifat mobile dan mudah untuk tercuci sehingga ketersediaan $\mathrm{N}$ di dalam tanah menjadi rendah. Hal tersebut menyebabkan pertumbuhan tanaman menjadi tidak optimal dan mempengaruhi produktivitas tanaman (Mukaromah et al., 2013). 
Penambahan pupuk N-anorganik merupakan salah satu cara untuk memenuhi kebutuhan hara $\mathrm{N}$ tanaman. Namun, penggunaan pupuk sintetik yang dilakukan tanpa mempertimbangkan kebutuhan tanaman dapat meningkatkan kadar $\mathrm{N}$ yang tercuci (Fikri et al., 2014). Kadar $\mathrm{N}$ yang tinggi pada sistem larutan tanah berpotensi untuk mencemari tanah dan air.

Urea merupakan pupuk $\mathrm{N}$ yang paling banyak digunakan untuk menyediakan hara $\mathrm{N}$ bagi tanaman, termasuk pada area sawah yang tergenang. Pupuk urea merupakan pupuk yang larut air, sehingga di dalam tanah akan segera larut dengan larutan tanah. Terdapat berbagai cara untuk menurunkan kelarutan urea, salah satunya dengan memodifikasi senyawa urea dan formaldehida agar memiliki rantai ikatan polimer yang lebih panjang (Lestari et al., 2013). Senyawa ureaform yang terbentuk dapat berupa seluruh senyawa urea atau hanya sebagai bahan penyalut butiran urea konvensional. Penyalutan tersebut dapat mempengaruhi pola kelarutan dan ketersediaan $\mathrm{N}$ dari urea. Selain itu, kelarutan urea juga dipengaruhi oleh faktor eksternal berupa kondisi lingkungan tempat pengaplikasian pupuk urea tersebut. Penelitian ini bertujuan mengevaluasi pelepasan $\mathrm{N}$ dari tipe urea yang konvensional dan urea yang diberi formaldehida pada kondisi tanah tergenang.

\section{BAHAN DAN METODE}

Penelitian berlangsung mulai bulan Agustus 2020 hingga Januari 2021 yang dilakukan di Laboratorium Divisi Kimia dan Kesuburan Tanah, Departemen Ilmu Tanah dan Sumberdaya Lahan, Fakultas Pertanian, IPB University. Bahan utama yang digunakan di dalam penelitian ini adalah tanah sawah Latosol dari Jasinga Bogor, pupuk urea Kujang, urea Pupuk Sriwijaya (Pusri), urea granul, urea prill, serta aquadest. Pupuk urea Kujang dan Pusri merupakan pupuk urea konvensional tanpa menggunakan lapisan formaldehida, sedangkan pupuk urea prill dan urea granul telah direaksikan dengan formaldehida sehingga memiliki kadar 0.10 dan 0.50 \% formaldehida. Pupuk urea Kujang memiliki ukuran yang sama dengan urea granul, dan urea Pusri memiliki ukuran yang sama dengan urea prill.

\section{Percobaan Inkubasi}

Metode inkubasi dan pencucian yang digunakan di dalam penelitian ini berdasarkan pada metode Stanford dan Smith (1972) yang dimodifikasi oleh Benedetti et al. (1993). Rancangan percobaan yang digunakan adalah rancangan acak lengkap dengan satu faktor. Tanah yang sudah dalam kondisi kering udara dicampur pasir kuarsa dengan perbandingan 1:1 (Gambar 1). Tanah yang sudah dicampur pasir kuarsa tersebut dimasukkan ke dalam tabung pencucian masing-masing seberat 500 g berat kering mutlak dengan dilapisi kain kasa di bagian bawahnya.
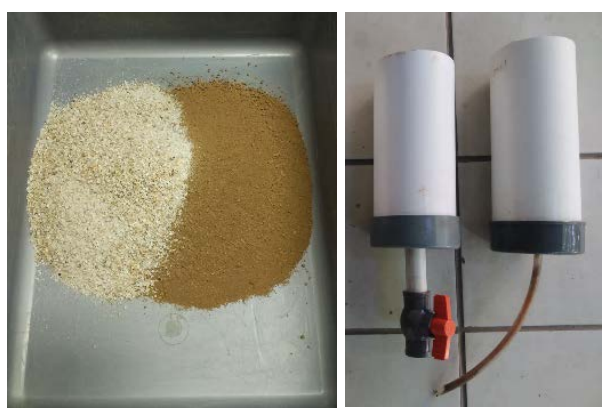

Gambar 1. Persiapan tanah, pasir dan tabung percobaan

Selanjutnya pada tabung pencucian diberikan perlakuan empat jenis pupuk urea masing-masing sebesar $125 \mathrm{mg} \mathrm{N}$ yang setara dengan $500 \mathrm{~kg}$ urea/ha, kemudian digenangi setinggi $2-3 \mathrm{~cm}$. Setiap perlakuan diulang sebanyak 3 kali. Tabung tersebut diletakkan di batang penyangga untuk mempermudah proses pencucian selama penelitian. Bahan-bahan tersebut ditempatkan di dalam ruang dengan suhu $\pm 30^{\circ} \mathrm{C}$ (suhu kamar) (Gambar 2).

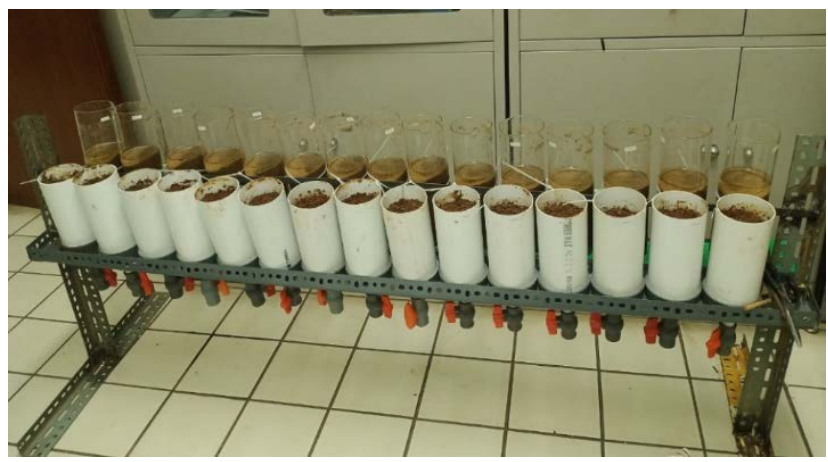

Gambar 2. Rancangan inkubasi tanah di dalam ruangan

Inkubasi dilakukan selama 7, 14, 28, 45, 60, dan 90 hari dan pada setiap akhir masa inkubasi dilakukan pencucian. Pencucian nitrat dan amonium dilakukan menggunakan larutan $0.01 \mathrm{~mol} \mathrm{~L}^{-1} \mathrm{CaSO}_{4}$ sebanyak $770 \mathrm{~mL}$ dan kemudian diteteskan $\mathrm{H}_{2} \mathrm{SO}_{4}$ pekat. Selama inkubasi, genangan dipertahankan setinggi 2-3 cm. Kontrol yang digunakan yaitu tanah tanpa pupuk urea. Leachate kemudian disaring dengan dengan kertas saring Whatman No. 42 dan dianalisis kadar amonium dan nitrat di laboratorium.

\section{Pengukuran Nitrat Sampel Pencucian}

Pengukuran konsentrasi nitrat dilakukan dengan mengukur absorban menggunakan spectrophotometer pada panjang gelombang $210 \mathrm{~nm}$ dan dikurangi $2.50 \mathrm{x}$ absorban pada panjang gelombang $275 \mathrm{~nm}$ sebagai koreksi bahan organik. Konsentrasi larutan standar nitrat yang digunakan adalah $0,1,2,4,6,8,10,12,16$ dan $20 \mathrm{mg} \mathrm{L}^{-1}$ nitrat.

\section{Pengukuran Amonium Sampel Pencucian}

Penetapan amonium dilakukan dengan metode destilasi. Leachate dipipet 25 mL kemudian dimasukkan ke dalam labu destilasi dan tambahkan $100 \mathrm{~mL}$ aquadest. Tambahkan 10 mL NaOH 50\% dengan gelas ukur ke dalam labu destilasi yang berisi sampel dan secepatnya ditutup. Hasil destilasi ditampung dalam erlenmeyer $250 \mathrm{~mL}$ yang 
telah diisi $10 \mathrm{~mL}$ asam borat $4 \%$ dan 3 tetes indikator Conway. Pada awal titrasi larutan berwarna merah muda dan proses destilasi dihentikan setelah volume larutan dalam erlenmeyer mencapai sekitar 50-75 mL dan larutan berwarna hijau. Destilat dititrasi dengan konsentrasi tepat $0.05 \mathrm{M} \mathrm{HCl}$ hingga berwarna merah muda. Data volume $0.05 \mathrm{M} \mathrm{HCl}$ digunakan untuk menghitung amonium.

\section{Analisis Data}

\section{Sidik Ragam}

Sidik ragam digunakan untuk mengetahui pengaruh perlakuan berbagai jenis pupuk urea terhadap pelepasan $\mathrm{N}$-tersedia pada tanah di kondisi tergenang. Uji beda nilai tengah dilakukan menggunakan Uji Tukey pada taraf alpha $<0.05$. Aplikasi yang digunakan untuk melakukan sidik ragam dan uji beda nilai tengah adalah Minitab 19.

\section{Persamaan First Order Kinetic}

Persamaan first order kinetic (Persamaan 1) digunakan untuk mendapatkan nilai maksimum $\mathrm{N}$ yang dilepaskan dan konstanta kecepatan pelepasan $\mathrm{N}$ dari masing-masing jenis pupuk urea. Aplikasi yang digunakan untuk memperoleh hasil dari persamaan tersebut adalah SigmaPlot 14.0.

$$
\mathrm{y}=\mathrm{a}\left(1-\mathrm{e}^{-\mathrm{kt}}\right)
$$

dimana, $\mathrm{y}$ adalah jumlah kumulatif $\mathrm{N}$ yang tercuci (mg tabung $\left.^{-1}\right) ; \mathrm{a}=$ maksimum $\mathrm{N}$ yang tercuci (mg tabung ${ }^{-1}$ ); $\mathrm{k}=$ konstanta kecepatan hari ${ }^{-1}$ ), dan $\mathrm{t}=$ waktu (hari).

\section{HASIL DAN PEMBAHASAN}

\section{Pola Pelepasan Amonium dan Nitrat di Tanah Tergenang}

Pelepasan amonium sudah terjadi sejak hari pertama inkubasi. Pada 28 hari inkubasi, kelarutan amonium pada perlakuan urea Kujang dan Pusri memiliki nilai lebih tinggi dibandingkan dengan perlakuan lainnya (Tabel 1). Kondisi sebaliknya diperoleh pada kelarutan 45 hingga 90 hari inkubasi, yang menunjukkan bahwa urea granul dan prill mempunyai kelarutan lebih tinggi. Hal tersebut menunjukkan bahwa penambahan formulasi formaldehida dapat mempengaruhi kelarutan urea yaitu pada awal waktu inkubasi.

Perbedaan pola tersebut disebabkan karena urea formaldehida memiliki ikatan rantai yang lebih panjang dibanding pupuk urea konvensional. Hal tersebut mengakibatkan penguraian formaldehida membutuhkan waktu yang lebih lama yang berlangsung sekitar 28 hari. Pupuk modifikasi formaldehida memiliki kemampuan memperlambat penguraian urea pada empat minggu pertama setelah pengaplikasian pupuk (Tabel 1).

Pada kondisi tanah tergenang, konsentrasi oksigen berada pada jumlah terbatas. Akibatnya bentuk amonium menjadi dominan. Amonifikasi N-organik dapat terjadi pada kondisi anaerob, namun nitrifikasi memerlukan ketersediaan oksigen dalam kondisi yang cukup agar amonium dapat berubah menjadi nitrat. Oleh karena itu, senyawa $\mathrm{N}$-anorganik pada kondisi anaerob didominasi oleh amonium (Hardjowigeno, 2003). Setelah proses amonifikasi yang terjadi di dalam tanah seperti yang dikemukakan di atas, kemudian dilanjutkan proses nitrifikasi sehingga dapat terbentuk nitrat.

Konsentrasi nitrat baru meningkat cukup jelas setelah 28 hari inkubasi, berbeda dengan amonium tercuci yang sudah terlarut sejak awal inkubasi (Tabel 1 dan Tabel 2). Perlakuan urea menghasilkan kadar nitrat yang lebih tinggi dibandingkan kontrol, namun secara statistik tidak berbeda nyata (Tabel 2). Kelarutan nitrat yang meningkat setelah 28 hari inkubasi menunjukkan bahwa diperlukan waktu yang lebih lama untuk mengoksidasi amonium menjadi nitrat setelah urea larut pada tanah tergenang. Pola kelarutan nitrat yang terjadi dalam penelitian ini relatif sama, yaitu meningkat sampai 45 hari inkubasi kemudian cenderung tetap hingga akhir inkubasi.

Berdasarkan hasil penelitian Mawaddah et al. (2016), penggunaan urea pada tanah tergenang tidak terlalu berpengaruh terhadap kelarutan nitrat di dalam tanah. Berbeda dengan Hartono et al. (2019) yang mendapatkan pelepasan nitrat yang dominan dibandingkan amonium pada percobaan kinetika pelepasan $\mathrm{N}$ pupuk pelet berbahan dasar lumpur kolam ikan pada keadaan aerob. Pada kondisi tanah tergenang kadar oksigen sangat rendah sehingga kemampuan bakteri nitrosomonas dan nitrobacter dalam mengoksidasi amonium menjadi nitrit dan nitrat mengalami penurunan. Pada penelitian ini, perubahan amonium menjadi nitrit dan nitrat efektif terjadi pada 28 hari inkubasi (Tabel 2). Kadar nitrat dalam sistem terbuka pada tanah tergenang dapat menurun akibat laju konsumsi oksigen oleh bakteri berlangsung lebih cepat dibandingkan laju difusi oksigen dari atmosfer ke dalam tanah. Hal tersebut dapat menyebabkan terjadinya proses denitrifikasi. Nitrat akan mengalami reduksi menjadi gas $\mathrm{N}_{2} \mathrm{O}$ dan berubah menjadi gas $\mathrm{N}_{2}$ (Indriyati et al., 2008).

Tabel 1. Kadar $\mathrm{N}-\mathrm{NH}_{4}{ }^{+}$tercuci kumulatif

\begin{tabular}{|c|c|c|c|c|c|c|}
\hline \multirow{3}{*}{ Perlakuan } & \multicolumn{6}{|c|}{ Waktu Inkubasi } \\
\hline & 7 hari & 14 hari & 28 hari & 45 hari & 60 hari & 90 hari \\
\hline & \multicolumn{6}{|c|}{ 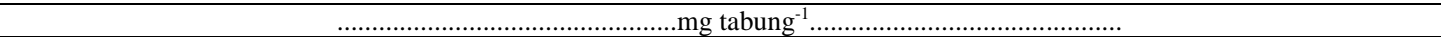 } \\
\hline Kontrol & $2.82 \mathrm{a}$ & $5.28 \mathrm{a}$ & $11.0 \mathrm{~b}$ & $11.9 \mathrm{~b}$ & $12.0 \mathrm{~b}$ & $12.4 \mathrm{~b}$ \\
\hline Pusri & $9.68 \mathrm{a}$ & 18.0a & $41.1 \mathrm{a}$ & $48.0 \mathrm{a}$ & $50.2 \mathrm{a}$ & $51.9 \mathrm{a}$ \\
\hline Granul & $13.2 \mathrm{a}$ & $23.5 a$ & 40.1ab & 51.5a & $55.0 \mathrm{a}$ & $58.6 a$ \\
\hline Prill & $12.7 \mathrm{a}$ & 22.3a & 38.2ab & $55.0 \mathrm{a}$ & $60.9 a$ & $63.9 \mathrm{a}$ \\
\hline
\end{tabular}

Keterangan : Angka-angka yang diikuti huruf yang sama dalam satu kolom tidak berbeda nyata pada uji Tukey dengan alpha $<0.05$ 


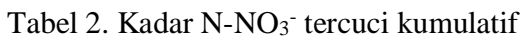

\begin{tabular}{|c|c|c|c|c|c|c|}
\hline \multirow{3}{*}{ Perlakuan } & \multicolumn{6}{|c|}{ Kadar $\mathrm{N}-\mathrm{NO}_{3}{ }^{-}$} \\
\hline & 7 hari & 14 hari & 28 hari & 45 hari & 60 hari & 90 hari \\
\hline & \multicolumn{6}{|c|}{ 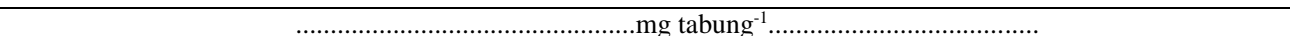 } \\
\hline Kontrol & 0.04 & 0.04 & 1.51 & 8.18 & 8.78 & 8.82 \\
\hline Kujang & 0.05 & 0.33 & 5.26 & 15.6 & 17.0 & 17.1 \\
\hline Pusri & 0.00 & 0.06 & 1.17 & 10.6 & 16.4 & 16.6 \\
\hline Granul & 0.03 & 0.03 & 3.78 & 17.6 & 19.3 & 19.3 \\
\hline Prill & 0.06 & 0.19 & 3.97 & 10.1 & 11.3 & 11.3 \\
\hline
\end{tabular}

\section{Dinamika Pola Pelepasan Total N-Tersedia di Tanah Anaerobik}

Dinamika pola pelepasan N-tersedia kumulatif disajikan pada Tabel 3. Pola pelepasan kadar total Ntersedia serupa dengan pola pelepasan amonium.

Pelepasan total N-tersedia sudah terjadi sejak 7 hari inkubasi (Tabel 3). Kemudian terjadi peningkatan yang signifikan pada 28 hari inkubasi, dengan perlakuan urea yang nyata lebih tinggi dibandingkan perlakuan kontrol. Kondisi yang sama terjadi pada 45 hingga 90 hari inkubasi. Pada 28 hari inkubasi total N-tersedia kumulatif tertinggi dijumpai pada perlakuan urea Kujang dan pada sisa hari inkubasi urea modifikasi granul dan prill memiliki kelarutan $\mathrm{N}$ yang lebih tinggi dibandingkan perlakuan yang lain.

Reaksi urea yang terjadi di dalam tanah diawali oleh reaksi hidrolisis. Kecepatan urea terhidrolisis akan sangat bergantung pada kondisi tanah. Secara umum, urea akan mulai terhidrolisis pada lima hari setelah pengaplikasian (Sholikah et al., 2013). Setelah terhidrolisis, pupuk urea akan membentuk amonium hingga akhirnya ternitrifikasi menjadi nitrat ketika dijumpai kondisi aerobik.

Perbedaan kelarutan antar pupuk urea dapat dipengaruhi oleh faktor fisik dan kimia. Pengaruh faktor fisik dapat dilakukan dengan mengatur ukuran butir dari pupuk urea (Shaviv, 2000). Semakin besar luas permukaan pupuk urea, maka urea akan semakin cepat terlarut di dalam tanah. Faktor kimia yang mempengaruhi proses kelarutan hara adalah kondisi lingkungan dan bahan pelapis yang digunakan pada pupuk urea (Haq et al., 2012).
Pola pelepasan $\mathrm{N}$ kumulatif tertinggi dijumpai pada perlakuan pupuk urea granul, kemudian dilanjutkan urea prill, urea Kujang, urea Pusri dan kontrol (Gambar 3).

Setiap perlakuan pupuk urea memiliki pola pelepasan $\mathrm{N}$ yang serupa, dengan sedikit perbedaan yang tidak signifikan (Gambar 3). Pelepasan $\mathrm{N}$ terjadi sejak 7 hari inkubasi, dan mulai stagnan setelah 45 hari inkubasi. Berdasarkan gambar tersebut, dapat terlihat bahwa nilai pelepasan $\mathrm{N}$ pada tanah dengan perlakuan pupuk urea memiliki nilai yang berbeda secara signifikan terhadap perlakuan kontrol.

Berdasarkan hasil total $\mathrm{N}$ tercuci selama 90 hari, nilai paling tinggi diperoleh pada perlakuan granul sebesar 77.9 mg tabung $^{-1}$, kemudian dilanjutkan dengan prill 75,24 mg tabung ${ }^{-1}$, Kujang 71,6 mg tabung ${ }^{-1}$, dan Pusri 68,43 mg tabung $^{-1}$. Berdasarkan penelitian Yamamoto et al. (2016) diketahui bahwa kelembaban tanah mempengaruhi kelarutan hara pada pupuk urea konvensional dan urea formaldehida. Hal tersebut menunjukkan bahwa kondisi lingkungan tanah berpengaruh terhadap pelepasan $\mathrm{N}$ dari pupuk urea.

\section{Laju dan Pola Pelepasan Nitrogen}

Parameter persamaan first order kinetic pelepasan $\mathrm{N}$-tersedia menunjukkan pelepasan maksimum (nilai a) pada tiap-tiap perlakuan (Tabel 4). Nilai pelepasan tertinggi dihasilkan oleh perlakuan granul sebesar 94.6, kemudian diikuti dengan pupuk prill sebesar 88.3 mg tabung ${ }^{-1}$, Pusri 82.3 mg tabung $^{-1}$, dan Kujang 79.2 mg tabung $^{-1}$.

Tabel 3. Kadar total N-tersedia kumulatif

\begin{tabular}{|c|c|c|c|c|c|c|}
\hline \multirow{3}{*}{ Perlakuan } & \multicolumn{6}{|c|}{ Waktu Inkubasi } \\
\hline & 7 hari & 14 hari & 28 hari & 45 hari & 60 hari & 90 hari \\
\hline & \multicolumn{6}{|c|}{ 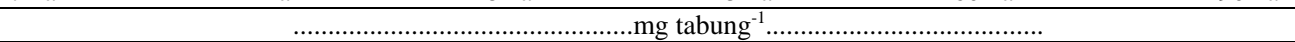 } \\
\hline Kontrol & $2.86 a$ & $5.32 \mathrm{a}$ & $12.5 b$ & $20.1 b$ & $20.7 \mathrm{~b}$ & $21.2 b$ \\
\hline Kujang & $13.6 \mathrm{a}$ & 23.6a & $50.2 \mathrm{a}$ & $67.4 \mathrm{a}$ & $69.3 a$ & $71.6 \mathrm{a}$ \\
\hline Pusri & $9.68 \mathrm{a}$ & $18.0 \mathrm{a}$ & 42.2ab & $58.1 \mathrm{a}$ & $66.6 \mathrm{a}$ & $68.4 \mathrm{a}$ \\
\hline Granul & $13.2 \mathrm{a}$ & $23.5 \mathrm{a}$ & 43.8ab & 69.1a & $74.2 \mathrm{a}$ & $78.0 \mathrm{a}$ \\
\hline Prill & $12.7 \mathrm{a}$ & $22.5 a$ & $42.2 \mathrm{ab}$ & 65.1a & $72.2 \mathrm{a}$ & $75.2 \mathrm{a}$ \\
\hline
\end{tabular}

Keterangan : Angka-angka yang diikuti huruf yang sama dalam satu kolom tidak berbeda nyata pada uji Tukey dengan alpha $<0.05$ 


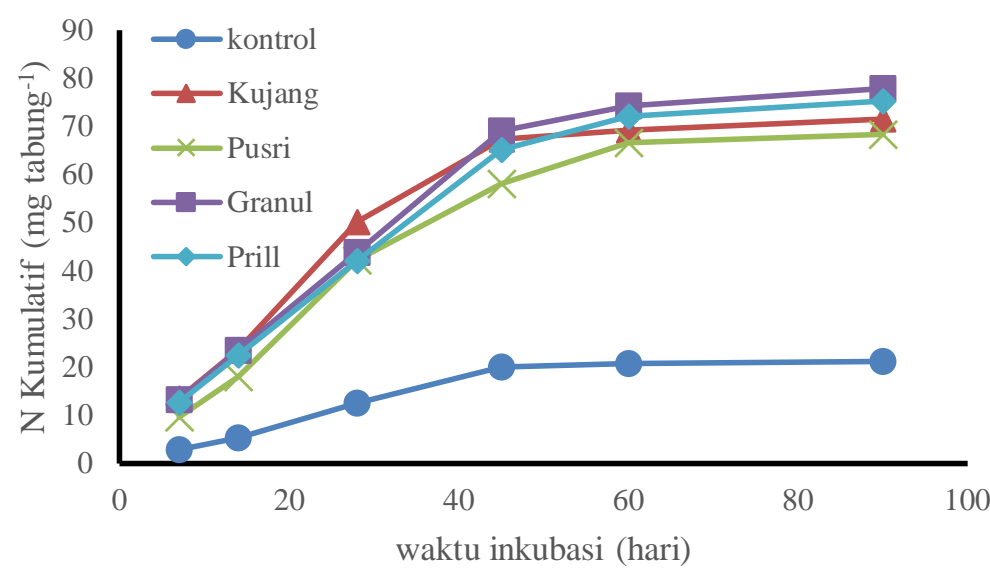

Gambar 3. Grafik dinamika N tercuci kumulatif

Tabel 4. Parameter persamaan first order kinetic pelepasan Ntersedia

\begin{tabular}{lcc}
\hline \multirow{2}{*}{ Perlakuan } & \multicolumn{2}{c}{ Parameter } \\
\cline { 2 - 3 } & $\mathrm{a}\left(\mathrm{mg} \mathrm{tabung}^{-1}\right)$ & $\mathrm{k}\left(\mathrm{hari}^{-1}\right)$ \\
\hline Kujang & 79.2 & 0.0349 \\
Pusri & 82.3 & 0.0256 \\
Granul & 94.6 & 0.0253 \\
Prill & 88.3 & 0.0256 \\
\hline
\end{tabular}

Berdasarkan hasil penelitian, diperoleh bahwa konstanta kecepatan pelepasan $\mathrm{N}$ pada perlakuan pupuk urea konvensional dan pupuk urea formaldehida tidak berbeda nyata (Tabel 4). Berdasarkan konstanta tersebut nilai konstanta kecepatan pelepasan $\mathrm{N}$ pada perlakuan Kujang sebesar 0.0349 hari $^{-1}$ dan nilai terendah dimiliki oleh perlakuan granul sebesar 0.0256 hari $^{-1}$. Data mengenai laju tersebut dapat dimanfaatkan untuk meminimalisasi kehilangan nitrogen di dalam tanah dengan menyesuaikan terhadap fase pertumbuhan tanaman (Zhang et al., 2021). Faktor utama yang diduga berpengaruh terhadap pelepasan $\mathrm{N}$ di dalam penelitian ini adalah kondisi tanah yang tergenang.

Berdasarkan data dan hasil yang telah disajikan, kadar total N-tersedia pada tanah tergenang didominasi oleh senyawa amonium. Kondisi tersebut disebabkan karena terhambatnya proses mineralisasi akibat karakteristik tanah yang tergenang (Dou et al., 1996). Tanah sawah yang tergenang, mempunyai lapisan tipis di permukaan yang bersifat aerobik. Pada lapisan tersebut terjadi proses nitrifikasi dan terbentuklah senyawa $\mathrm{NO}_{3}{ }^{-}$, sedangkan di bagian bawah memiliki kondisi tanah yang anaerob.

Efektivitas dari lapisan polimer formaldehida pada pupuk urea dapat semakin menurun karena terurai akibat intensitas air dan jenis mikrob pada tanah tergenang (Salthammer and Gunschera, 2021). Selain itu, konsentrasi formaldehida sebesar 0.10 dan $0.50 \%$ pada pupuk urea modifikasi prill dan granul diperkirakan masih cukup minim. Oleh karena itu, sifat kelarutan pupuk modifikasi formaldehid pada tanah tergenang tidak berbeda secara statistik dengan urea konvensional yaitu Kujang dan Pusri.

\section{SIMPULAN}

Pengaruh jenis pupuk urea terhadap pelepasan $\mathrm{N}$ dalam bentuk amonium dan nitrat tidak berbeda nyata. Total $\mathrm{N}$ tercuci paling tinggi diperoleh oleh urea granul sebesar $78.0 \mathrm{mg}$ tabung $^{-1}$, kemudian disusul oleh urea prill $75.2 \mathrm{mg}$ tabung $^{-1}$, urea Kujang sebesar 71.5 mg tabung ${ }^{-1}$, dan urea Pusri sebesar $68.4 \mathrm{mg}$ tabung ${ }^{-1}$.

Berdasarkan hasil persamaan first order kinetic, diperoleh nilai pelepasan maksimum tertinggi dimiliki oleh urea granul sebesar 94.6 mg tabung $^{-1}$, kemudian diikuti oleh urea prill sebesar $88.3 \mathrm{mg}^{\text {tabung }}{ }^{-1}$, urea Pusri sebesar 82.3 mg tabung ${ }^{-1}$, dan urea Kujang sebesar 79.2 mg tabung $^{-1}$. Sementara untuk nilai konstanta kecepatan, konstanta kecepatan pelepasan $\mathrm{N}$ tertinggi diperoleh pada urea Kujang sebesar 0.0349 hari $^{-1}$, kemudian diikuti oleh urea prill dan Pusri sebesar 0.0256 hari $^{-1}$, dan urea granul sebesar 0.0253 hari $^{-1}$.

Hasil penelitian menunjukkan bahwa urea yang diperlakukan dengan formaldehida dalam bentuk granul walaupun secara statistik tidak berbeda nyata cenderung memiliki kemampuan untuk memperlambat proses pelepasan $\mathrm{N}$ yang ditunjukkan dengan nilai konstanta kecepatan pelepasan $\mathrm{N}$ yang paling rendah.

\section{UCAPAN TERIMA KASIH}

Penulis mengucapkan terima kasih kepada Direktur PT. Pupuk Kaltim atas dana penelitian yang diberikan dan juga kepada teknisi laboratorium dan rumah kaca Departemen Ilmu Tanah dan Sumberdaya Lahan, Fakultas Pertanian, IPB University sehingga penelitian ini dapat diselesaikan.

\section{DAFTAR PUSTAKA}

Benedetti, A. and G. Sebastiani. 1993. Determination of potentially mineralizable nitrogen in agriculture soil. Biol. Fertil. Soil, 21: 114-120.

Dou, Z., J.D. Toth, J.D. Jabro, R.H. Fox, and D.D. Fritton. 1996. Soil nitrogen mineralization during laboratory incubation: Dynamics and model fitting. Soil Biol. Biochem., 28(4-5): 625-632.

Fikri, U., Marsudi, dan D.R. Jati. 2014. Pengaruh penggunaan pupuk terhadap kualitas air tanah di lahan pertanian kawasan rawa Rasau Jaya 3, Kab. Kubu Raya. Jurnal Teknologi Lingkungan Lahan Basah, 2(1): 1-10.

Haq, M.A., S. Triwiningsih dan Suherman. 2012. Pembuatan urea pelepasan lepas lambat melalui 
pelapisan dengan amilum-acrylic menggunakan teknologi fluidized bed spray. Jurnal Teknologi Kimia dan Industri, 1(1): 229-236.

Hardjowigeno, S. 2003. Ilmu Tanah. Akademika Pressindo. Jakarta.

Hartono, A., L.T. Indriyati, P.T. Santari dan N.E. Novianti. 2019. Perubahan sifat kimia dan pola pelepasan amonium dan nitrat pada Ultisol Darmaga yang diberi pupuk pelet berbahan dasar lumpur kolam ikan. J. Il. Tan. Lingk., 21(2): 78-86.

Indriyati, L.T., S. Sabiham, L.K. Kadarusman, T. Situmorang, Sudarsono dan W.H. Sisworo. 2008. Transformasi nitrogen dalam tanah tergenang: aplikasi jerami padi dan kompos jerami padi. Jurnal Tanah Tropika, 13(3): 189-197.

Leiwakabessy, F.M. 1988. Kesuburan Tanah. Departemen Tanah, Fakultas Pertanian, IPB. Bogor.

Lestari, R.S., D. Rochmadi dan Supranto. 2013. Pelepasan lambat (slow release) diazinon dari mikrokapsul melamin urea formaldehida. Jurnal Rekayasa Proses, 7(2): 31-36.

Mawaddah, A., Roto dan A. Suratman. 2016. Pengaruh penambahan urea terhadap peningkatan pencemaran nitrit dan nitrat dalam tanah. Jurnal Manusia dan Lingkungan, 23(3): 360-364.

Mukaromah, L., T. Nurhidayati dan S. Nurfadilah. 2013. Pengaruh sumber dan konsentrasi nitrogen terhadap pertumbuhan dan perkembangan biji Dendrobium laxiflorum J.J Smith secara in vitro. Jurnal Sains dan Seni POMITS, 2(1): 26-29.

Mulyani, N.S., M.E. Suryadi, S. Dwiningsih dan Haryanto. 2001. Dinamika hara nitrogen pada tanah sawah. Jurnal Tanah dan Iklim, 19: 14-25.

Prasad, R. and S.K. De Datta. 1979. Increasing fertilizer nitrogen efficiency in wetland rice. In International
Rice Research Institute Nitrogen and Rice. Los Baños, Laguna, Philippines. p. 465-484.

Salthammer, T. dan J. Gunschera. 2021. Release of formaldehyde and other organic compounds from nitrogen fertilizer. Journal of Chemosphere, 263: 18.

Shaviv, A. 2000. Advances in controlled release fertilizer. Advances in Agronomy, 71:1-49.

Sholikah, M.H., Suyono dan P.R. Wikandari. 2013. Efektivitas kandungan unsur hara $\mathrm{N}$ pada pupuk kandang hasil fermentasi kotoran ayam terhadap pertumbuhan tanaman terung (Solanum Melongena L.). Journal of Chemistry, 2(1):131-136.

Situmorang, R. dan U. Sudadi. 2001. Tanah Sawah. Jurusan Tanah. Fakultas Pertanian. Institut Pertanian Bogor. 105 hal.

Soepardi, G. 1983. Sifat dan Ciri Tanah. IPB Press. Bogor.

Stanford, G. and S.J. Smith. 1972. Nitrogen mineralization potentials of soils. Soil Sci.Soc.Am.Proc., 36: 465472.

Suparto, H. 2018. Kehilangan nitrogen pada sistem usahatani jagung manis di lahan gambut kalimantan tengah. Jurnal Agripeat, 19 (1): 51-58.

Yamamoto, C.F., E.I. Pereira, L.H.C. Mattoso, T. Matsunaka and C. Ribeiro. 2016. Slow release fertilizer based on urea/urea-formaldehyde polymer nanocomposites. Chemical Engineering Journal, 287: 390-397.

Zhang, J., P. He, W. Ding, S. Ullah, T. Abbas, M. Li, C. Ai and W. Zhou . 2021. Identifying the critical nitrogen fertilizer rate for optimum yield and minimum nitrate leaching in a typical field radish cropping system in china. Journal of Environmental Pollution, 268: 1-10. 